\title{
Resin recovery and the use of computed tomography for quantitative image analysis of railway ballast
}

\author{
L. Le Pen ${ }^{1}$, S. Ahmed ${ }^{1}$, A. Zervos ${ }^{1}$ J. Harkness ${ }^{1}$ and W. Powrie ${ }^{1}$ \\ ${ }^{1}$ Faculty of Engineering and the Environment, University of Southampton, SO17 1BJ, UK.
}

\begin{abstract}
Over its life cycle, railway ballast undergoes changes to its fabric structure due to train loading and maintenance (e.g. tamping). Understanding these changes and linking them quantitatively to the loading regime has the potential to inform improved designs for new track and more cost-effective maintenance of the existing network. However, a method for recovering samples of ballast from in service track with the fabric structure preserved for detailed examination is required. This paper describes the development and application of such a method using a polyurethane resin, and demonstrates the ability of powerful X-ray scanners and CT (computed tomography) techniques to construct 3D images of recovered samples up to $300 \mathrm{~mm}$ in diameter. It is believed that obtaining preserved samples from in-service railway track and using CT scanning on such large samples have not been done before. To demonstrate the quality and versatility of the CT images illustrative results for CT analysis to measure the coordination number and particle orientation of the field samples obtained are also presented.
\end{abstract}

Keywords: Fabric, structure, railway ballast, element testing, computed tomography.

\section{Introduction and Background}

The influence of the fabric component of structure (i.e. the spatial arrangement of particles and associated voids) on the mechanical behaviour of natural soils has long been recognized (e.g. [1, 2, 3, 4]). Fabric is also increasingly being recognised as important in the behaviour of placed materials such as embankment fills [5] and railway ballast; an application in which fabric is likely to change over time as a result of trafficking and periodic maintenance.

A better understanding of ballast mechanics is needed to facilitate the costeffective maintenance of existing railways and inform the design of new high speed 
lines. The development of such an understanding requires knowledge of ballast fabric, which in turn requires the recovery of samples of ballast with the fabric preserved. Recovery of preserved samples holds particular difficulties for railway ballast because of the relatively large particle size, usually in the range $22.4 \mathrm{~mm}$ to $62.5 \mathrm{~mm}$. While most clays and locked sands [6] can be recovered intact with careful handling, unbonded and unlocked sands and gravels cannot. Ground freezing techniques (see e.g. [7]) have been used for the recovery of intact sand samples over a number of decades but they have yet to be successfully adapted to larger grain sized materials such as ballast. Also, such methods are costly and their application requires unrestricted site access that is impractical to arrange on an operational railway line. Although frozen recovered samples of sand can be trimmed for laboratory testing, this is not the case for samples of railway ballast, owing to the large grain size.

Another possibility is to preserve samples for recovery and examination using a suitable resin or glue. The use of resins or glues to preserve fabric in samples has been attempted over the past few decades. [8] used epoxy resin to preserve laboratory-prepared samples of railway ballast and carried out mechanical sectioning of these samples, which were then evaluated qualitatively in terms of particle interlocking and void characteristics for different gradations. [9] used hypodermic needles to inject resin into small samples of sand in the laboratory to evaluate variations in density. PolyVinylAcetate (PVA) glue has been used for preserving laboratory samples of sands and other relatively fine grained materials for investigations into the influence of particle shape on packing and the nature of particle contacts; e.g. $[10,11,12]$. However, few if any attempts have been made to use resins or glues to the recover fabric preserved field samples.

Preserved samples held in resin or glue can be scanned using computed tomography $(\mathrm{CT})$ to render all particles individually in $3 \mathrm{D}$; thus providing all the spatial data necessary for the evaluation of fabric. The use of CT scans to examine preserved laboratory samples of sands has been well documented; and has extended to scanning samples at various stages within tests to document the development of shear bands and strain localisation. However, the use of CT to date has been on small samples of clays, sands and silts (see e.g. [13]) and the application of CT to significantly larger preserved samples of railway ballast has not previously been attempted.

This paper describes and demonstrates how to:

1.recover preserved samples of railway ballast from the field on operational railway lines during scheduled maintenance

2. apply CT scanning to large sized samples of railway ballast.

It also presents initial CT results of coordination number and particle orientation, and discusses some of the difficulties in determining these quantitative measures of fabric structure.

\section{Recovery of Samples}


Ballast in railway track may be located between the sleepers ("crib ballast"), in a "shoulder" at the sleeper ends, or beneath the sleepers ("base ballast"): Figure 1. The most significant changes in structure are expected in the base ballast owing to the passage of many tens of millions of cumulative tonnes of train axle loads ${ }^{1}$. Sampling of the most heavily loaded ballast from beneath the railseat (shown shaded in Figure 1) requires the sleeper to be removed, which is difficult to arrange but does occur routinely during track maintenance such as renewals.

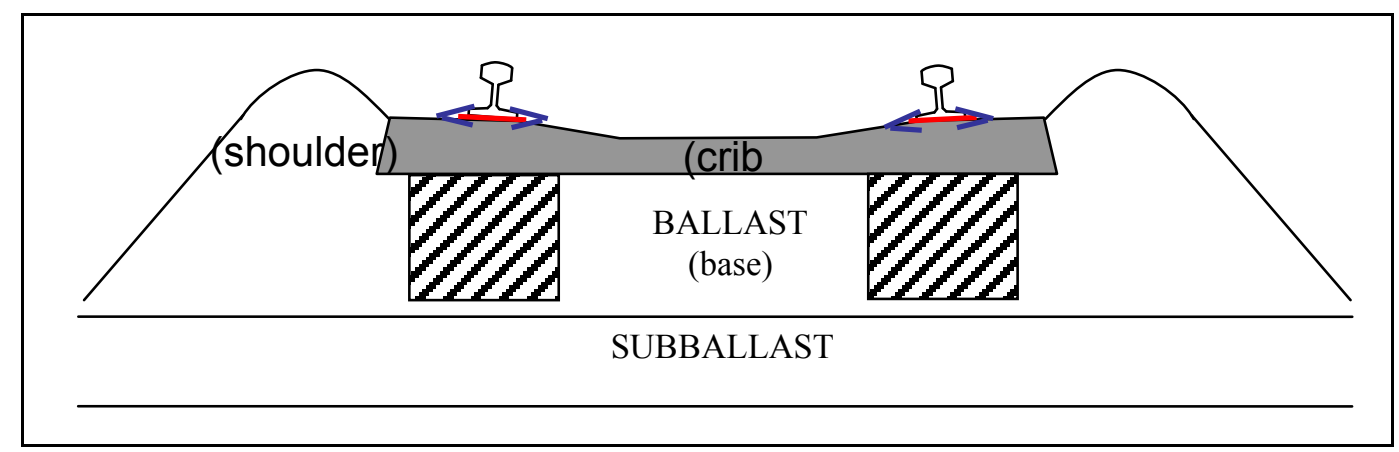

Figure 1: Ballast to be sampled (hatched region beneath railseats).

A method has been developed to recover a fabric-preserved sample of approximate dimensions $300 \mathrm{~mm} \times 300 \mathrm{~mm} \times 300 \mathrm{~mm}$ from below the sleeper railseat. It is conceptually simple; a polyurethane resin is introduced into the ballast to bind the particles in place, so the fabric remains the same during sample removal. In practice, however, significant challenges had to be overcome in part, not least in order to carry out the technique on an operational railway line.

The viscosity and curing time of the resin, as well as the quantity used, must satisfy conflicting requirements. The resin must be fluid enough to move through the voids in the ballast layer, but viscous enough not to disperse too far below the intended sampling depth before curing to a strength sufficient for sample removal. The curing time should be as short as possible to minimize disruption to operation railway lines, but long enough for the resin to reach the required depth.

A number of tests on laboratory samples showed that polyurethane resin EL366D/NC [14] mixed with a chalk filler to increase viscosity satisfies these requirements. At $25^{\circ} \mathrm{C}$ it has an initial viscosity without filler of less than $200 \mathrm{mPa} . \mathrm{s}$ and a useable time of 2 minutes. Samples have been obtained at temperatures as low as $5^{\circ} \mathrm{C}$. While there are probably a number of resins that would be suitable for the sampling process the main advantage of resin EL366D/NC over other resins trialed was the short cure time, which was key to sampling on operational lines during planned overnight maintenance works. The resin is also advertised as having a dimensional stability and low shrinkage [14]. The resin was supplied by Robnor in 2 $\mathrm{kg}$ kits consisting of $1 \mathrm{~kg}$ of resin and $1 \mathrm{~kg}$ of hardener to be mixed together (data sheets are available from [14]). The chalk was also supplied by Robnor in $3 \mathrm{~kg}$ tubs. The quantity of chalk used varied but may be estimated as approximately $1 / 4$ of the final mixture by weight.

${ }^{1}$ On busy lines 10 million tonnes per year is possible. 
A quick and reasonably reproducible on site method for fixing and removing the sample is also needed. To help control the pouring area, hence the size of the resin bulb, a $4 \times 4$ metal entry grid (Figure 2) was used; trials showed that an internal major dimension of $200 \mathrm{~mm}$ gives satisfactory results. By fixing lifting eyes onto the grid and overtopping the resin so that it bonds to it, samples can be recovered using a mechanical lifter.

A further potential concern is that expansion of the resin during curing may disturb the in-situ structure. In practice this concern has been proven unfounded. Adding the chalk filler and mixing it into the resin introduces a significant amount of air. After adding the hardener and pouring into the voids, the mixture generates heat and gradually becomes more viscous prior to full curing. While in a semi fluid state the mixture visibly expands, mainly as a consequence of the air introduced during mixing heating. Curing takes several minutes, during which time the mixture remains sufficiently fluid that expansion is taken up by movement into the voids or back out of the sample surface. The CT scans and mechanical slices along the sample edges demonstrate that there is no particle disturbance. Observation of the curing process on site indicated no uplift around the sampling locations, perhaps aided by the well compacted and horizontally confined nature of the ballast being sampled. It is also worth noting that the resin only bonds weakly with the ballast particles (which are usually damp and coated in dirt), with sample integrity maintained primarily by the crosslinked resin-filled network of voids. This last observation is consistent with the mechanism of support commonly associated with ballast gluing for track remediation.

The method is summarized below:

- A metal entry grid, comprising $4 \times 4$ sections each $200 \mathrm{~mm}$ squate, is placed onto the cleared ballast surface beneath the sleeper railseat (Figure 2).

- The resin is prepared in a bucket using a cordless drill with a stirring bit. It is first mixed with a chalk filler, normally as much as the resin will accept, to increase its viscosity. The hardener is then added, giving the mixture a treacle-like consistency. More chalk filler may be added but this is not usually necessary. Up to $8 \mathrm{~kg}$ of resin/hardener are needed, typically delivered in 2 to 3 pours, each being a separately prepared mixture. The first pour will consist of a $2 \mathrm{~kg}$ resin/hardener kit with chalk filler added, the second pour will be twice this quantity ( $4 \mathrm{~kg}+$ chalk filler) and the last pour (if needed) is a further $2 \mathrm{~kg}$ kit with chalk filler. This spacing of the pours allows the resin to cure sequentially and helps control the size of sample obtained with the initial pours coating the particles and closing off the voids by curing giving the later pours less freedom to flow out of the intended sample volume.

- After the resin has cured sufficiently (evaluated by timing, visual inspection and touch, and allowing some additional time for conservatism) the material around the resin bulb is excavated using a shovel to reduce resistance to lifting. 
- The sample is removed using a mechanical lifter, e.g. a Rail Road Vehicle (RRV) (Figure 3) within 30 minutes of the first pour.

- The sample is placed in a container and transported to the laboratory (Figure 4).

- At the laboratory the sample is placed into a plastic box and sealed by pouring more resin around it. The entry grid is levered off. The sample is then cut to a suitable shape, using a diamond saw (Figure 5).

The above method has been successfully applied at Arundel (within the station itself), New Milton (approximately $1.25 \mathrm{~km}$ west of the station) and High Marnham, all in England. Figures 2, 3 and 4, show the method being used at Arundel in May 2010. Sampling was facilitated by the well-defined boundary to the ballast bed provided by a clay layer approximately $250 \mathrm{~mm}$ below the sleeper base. Figure 5 shows the Arundel sample initially cut to a cube, and the New Milton sample cut to an octagonal cylinder with opposite faces $200 \mathrm{~mm}$ apart. Qualitative visual inspection indicated the Arundel sample to be relatively unfouled and the particles well packed. The New Milton sample was more fouled with less obviously welldefined contacts. Fouling was not heavy at any of the three sites, and it is recognized that the resin sampling technique may be less suitable for sites where heavy fouling has occurred. At New Milton and Arundel the ballast was of limestone, had last been renewed about 30 years previously and was recovered just prior to a track renewal being carried out overnight.

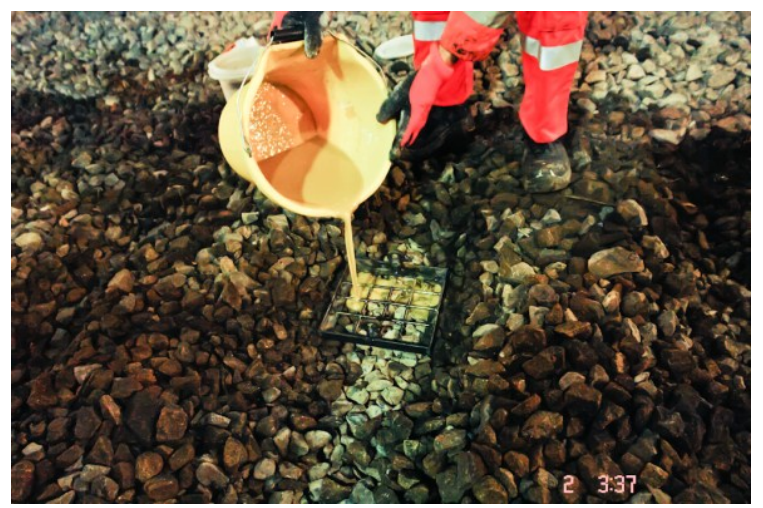

Figure 2: Resin being poured; Arundel, May 2010

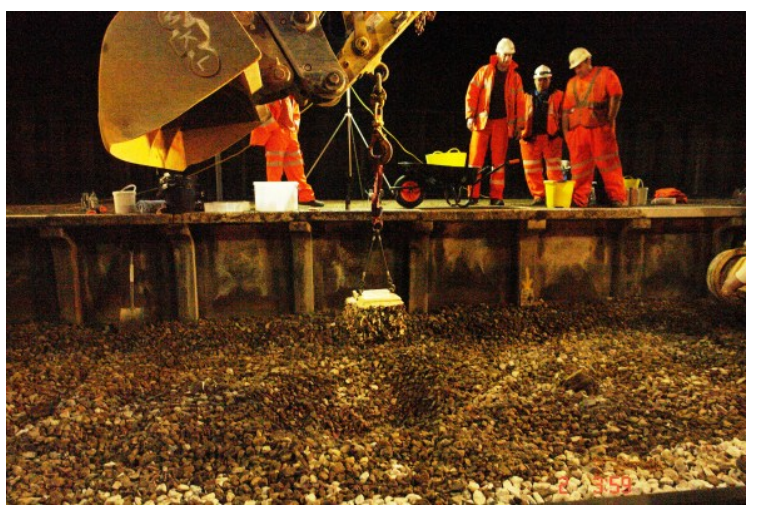


Figure 3: Sample being lifted out; Arundel, May 2010

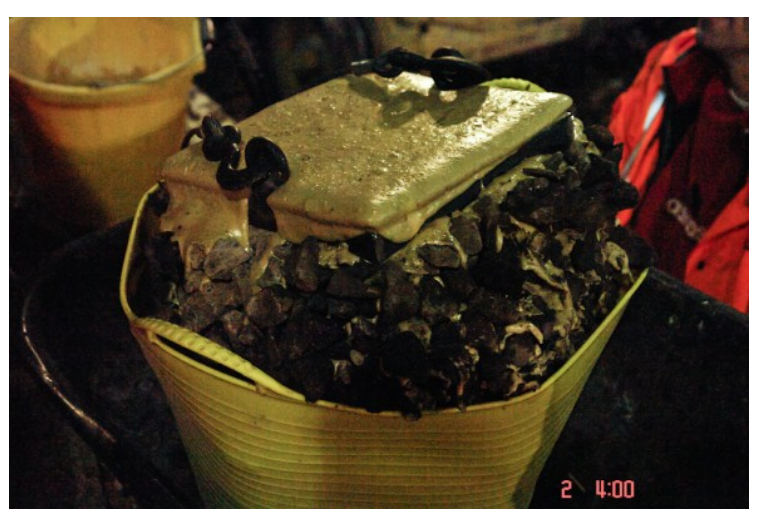

Figure 4: Sample placed in container for transport to laboratory; Arundel, May 2010
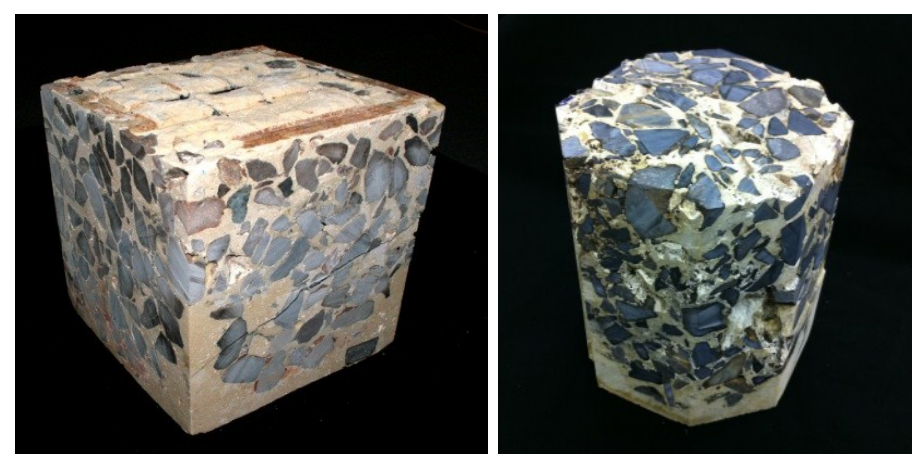

Figure 5: (a) Arundel sample cut to a $300 \mathrm{~mm}$ cube; (b) New Milton sample cut to octagonal cylinder

\section{CT scanning}

\subsection{Overview}

Advances in CT scanning render the traditional mechanical sectioning of samples of granular materials unnecessary. Micron-scale scan accuracy may be possible, but lower resolutions in proportion to ballast particle size are acceptable. The physical size and attenuating nature of the samples necessitates a high energy $\mathrm{X}$-ray source; in this case, a $450 \mathrm{kV}$ micro-focus source [15] was used. To obtain images of sufficient quality, field samples had to be cut to an octagonal cylinder with the opposite faces $<300 \mathrm{~mm}$ apart to reduce the X-ray path length and ensure its relative uniformity as the sample rotates inside the CT chamber (Figure 6). 


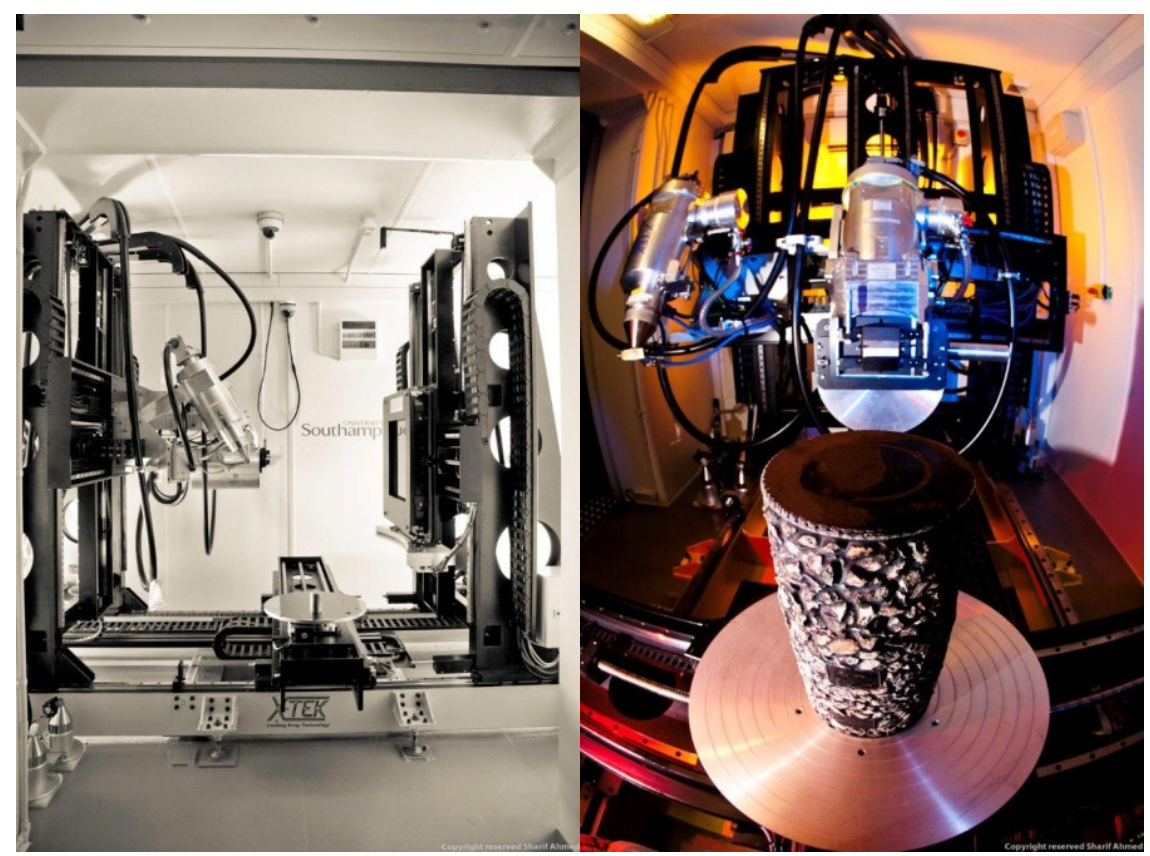

Figure 6: (a) $450 \mathrm{kV}$ hutch; (b) Wide angle view of triaxial sample ready for scanning

The principles of CT scanning as applied to soils and soil like materials are described in detail by $[13,16]$. The broad principles of suitable data processing techniques are summarised below.

\subsection{Data acquisition and processing}

Generating high resolution CT data sets for large dense objects such as ballast samples presents a significant technical challenge. The hard stone particles tend to scatter X-rays; unwanted artifacts were reduced through the use of a heavily collimated X-ray beam and a curved linear detector array. The focal spot of the particular X-ray source may be reduced to 50 microns at low power, however it is defocussed (spread) as the power is increased to avoid melting of the tungsten target. For the samples scanned, the resolution was determined by their diameter and the number of pixels on the detector. Scan times were minimised by reducing, as far as possible, the number of angular projections, frames per projection and the amount of filtration used. Table 1 reports the settings used; these were found to produce acceptable quality while minimising scan time and hence cost.

\begin{tabular}{|c|c|c|c|c|c|c|c|}
\hline $\begin{array}{c}\text { Scanned } \\
\text { item }\end{array}$ & $\begin{array}{c}\text { Voxel } \\
\text { size } \\
(\mathrm{mm})\end{array}$ & $\begin{array}{c}\text { Scan } \\
\text { Voltage } \\
(\mathrm{kV})\end{array}$ & $\begin{array}{c}\text { Scan } \\
\text { Current } \\
(\mathrm{uA})\end{array}$ & Filter & $\begin{array}{c}\text { Exposure } \\
(\mathrm{mSec})\end{array}$ & $\begin{array}{c}\text { No. } \\
\text { Projections }\end{array}$ & $\begin{array}{c}\text { Duration } \\
(\mathrm{hrs})\end{array}$ \\
\hline $\begin{array}{c}\text { New Milton: } \\
200 \mathrm{~mm} \\
\text { octagonal } \\
\text { prism (field } \\
\text { sample) }\end{array}$ & 0.29 & 440 & 525 & $\begin{array}{c}8 \mathrm{~mm} \\
\text { Copper }\end{array}$ & 0.18 & 865 & $\approx 52$ \\
\hline Arundel & 0.31 & 400 & 581 & $\begin{array}{c}8 \mathrm{~mm} \\
\text { Copper }\end{array}$ & 0.16 & 1201 & $\approx 24$ \\
\hline
\end{tabular}

Table 1: CT scan settings for the New Milton and Arundel 
The scans obtained render the images to approximately $0.3 \mathrm{~mm}$ accuracy (by voxel spacing). This is sufficient to capture the individual particle shape characteristics of form and roundness/angularity but not surface roughness (as defined by [17]), and to provide all the spatial information necessary for an evaluation of fabric.

Following established practice (e.g. [18]), commercial software (CT-Pro reference: [19]) was used to reconstruct images from the raw CT scan data ("sinograms".) These can be analysed using image (densitometric) processing techniques implemented in either commercial software (e.g. VSG Avizo Fire, version 7 ref: [20]) or bespoke code e.g. in Matlab [21].
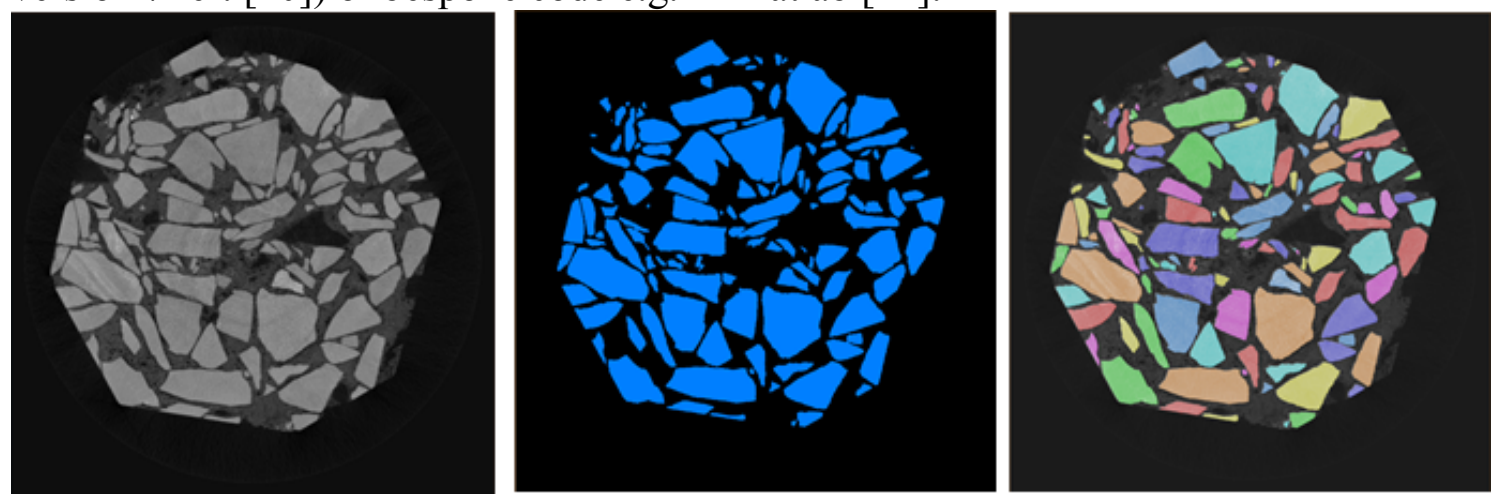

Figure 7: Image processing of the New Milton sample (a) original cleaned image,

(b) after segmentation (c) individual particles identifed

Following reconstruction the images may be filtered to clean them of unwanted artefacts. Median noise reduction and selective hole filling have been found to be suitable techniques. Once the images have been cleaned the ballast is identified by segmentation. The threshold values chosen for segmentation have an influence on the volume of material identified as ballast. Therefore, a trainable segmentation algorithm (TSA) was implemented in which each voxel is grouped into different classes (or phases) based on minimal user input. Initially, the user selects sets of pixels from a slice in the volume (usually the middle slice) and assigns each set to a class (e.g. background or ballast). The algorithm then builds a forest of classification trees by bootstrapping the feature data and assigned classes for the user chosen pixels. The forecast or classifier algorithm used is the Fast Random Forest which is a re-implementation of the Random Forest algorithm used in Weka [22, 23]. The classifier can then be used to segment the trained image and other images by applying the forest to each pixel. Further inputs by the user can allow the algorithm to 'learn' from the new sets of pixels and improve the forecast and classifier.

Where samples are fouled it may also be desirable to remove particles below a certain size. Figure 7a shows a slice through the New Milton sample; the light grey is the ballast, dark grey is the resin and black is air; black regions within the sample are air voids. The image is then segmented to isolate the ballast (Figure 7b) and connected particles are separated using a watershed algorithm (Figure 7c). Watershedding methods are described in [24 \& 25]. Figure 8 shows a 3D rendering of the New Milton sample following segmentation; resin and air are lightly shaded and ballast particles are darker. 
Further processing of the images obtained can be carried out to determine measurements related to fabric structure. In this paper we consider the coordination and orientation of particles only, although other measures of fabric structure such as contact normal orientation, contact classification (e.g. flat, concavo/convex, tangential, sutured etc, as described in Barton, 1994), the fabric tensor and the pore network may also be determined from the CT data.

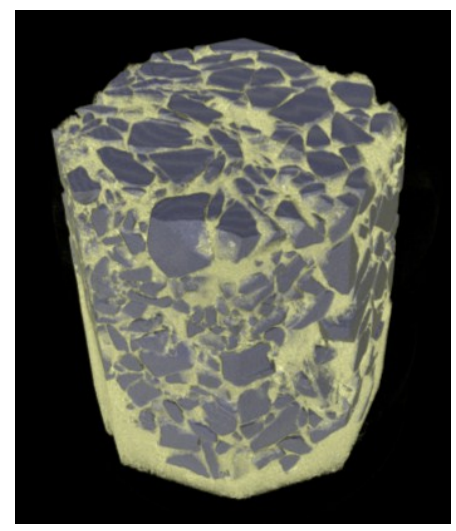

Figure 8: New Milton sample 3D render of ballast (darker) and resin (lighter) from CT scan2

\subsubsection{Coordination number}

The coordination number is the average number of contacts per particle and for sufficiently large samples can be quantified as:

$$
C N=2 \frac{N_{c}}{N_{p}}
$$

where $\mathrm{Nc}$ is the number of contacts and $\mathrm{Np}$ is the number of particles in the sample. Table 2 shows the calculated void ratio, porosity and coordination number for the two field samples.

\begin{tabular}{|l|l|l|l|}
\hline & Void ratio (e) & Porosity (n) & CN \\
\hline New Milton & 0.60 & 0.38 & 6.3 \\
\hline Arundel & 0.56 & 0.36 & 8.6 \\
\hline
\end{tabular}

Table 2: Basic quantitative data obtained from CT scans of granular aggregates.

Oda and Iwashita (1999) report average coordination numbers for assemblies of single sized spheres evaluated using an MRI scan of 6 . This may be compared with the coordination number for the samples in this study of 6.3 and 8.6 (Table 2). The larger coordination number of the Arundel sample is consistent with higher packing

\footnotetext{
${ }^{2}$ The top of the sample in Figure 8 is approximately $30 \mathrm{~mm}$ below the sleeper base.
} 
indicated by the lower void ratio. The New Milton sample had a lower packing density and lower coordination number, possibly as a result of the greater proportion of fouling material seen visually to be present, which was removed from the reconstructed CT scan. The increase above the value of 6 given by Oda and Iwashita 1999) for single sized spheres may be explained as a result of the irregular shapes and wider range of particle sizes present in the field samples.

\subsubsection{Orientation of particles from the horizontal}

The orientation is defined as the angle between the horizontal and the major particle dimension in 3D. To interpret the orientation data the results of a uniform orientation (the isotropic case) are first evaluated. This can be achieved by considering points on the surface of a sphere and calculating the distribution of the angle between them and a diametral plane taken as horizontal (Figure 9).
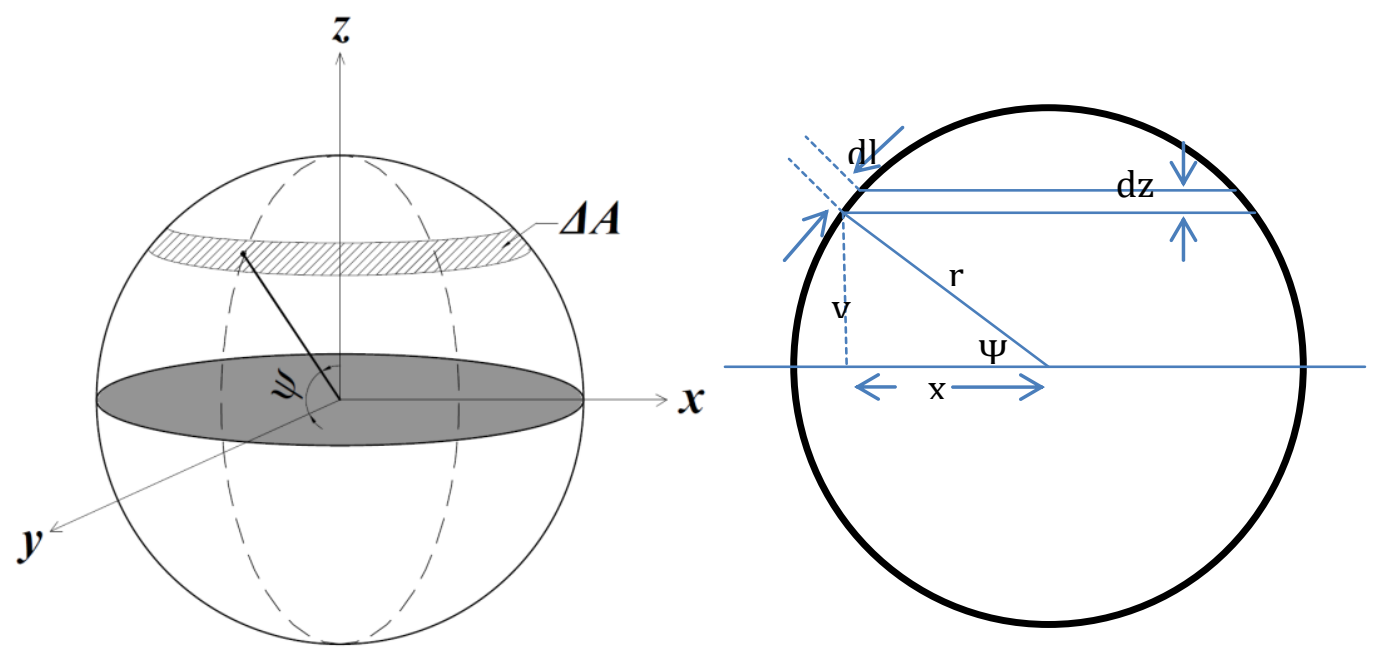

Figure 9: definition of orientation

Considering Figure 9, the surface area of the top hemisphere is the integral of the areas of all the trapezoidal rings from $\Psi=0$ to $\Psi=\pi / 2$ (or from $z=0$ to $z=r$ ). The area of a single ring is:

$$
\left.A_{\text {ring }}=2 \pi \mathrm{xd}\right]
$$

Geometrically,

$$
\frac{\mathrm{dl}}{d z}=\frac{r}{x}
$$

The ring area can be rewritten as:

$$
A_{\text {ring }}=2 \pi \mathrm{rdz}
$$

The area between two given heights $\mathrm{z}_{1}$ and $\mathrm{z}_{2}$ is then:

$$
A_{\text {band }}=2 \pi \mathrm{r} \int_{y_{1}}^{y_{2}} d z=2 \pi \mathrm{r}\left(z_{2}-z_{1}\right)
$$

In the isotropic case the number of orientations that lie in a given band will be proportional to the surface area of that band. Equation 5 shows that for equal height 
intervals the surface area of each band (and hence the proportions of particles present) is the same, but that for bands defined by equal intervals of angle the surface areas and hence the proportions of particles present will not be the same. Therefore if we choose to place the orientation data in equally sized angle increments, the proportion of orientations in equal size angle bands will decrease as the bands approach $90^{\circ}$ owing to the reduction in band surface area. However if the bands are applied as equal increments of height or $\sin \Psi$ there will be an equal proportion of particles in each band as shown in Table 3.

\begin{tabular}{|c|c|c|}
\hline $\begin{array}{c}\text { Bin heights as } \\
\text { proportion of radius }\end{array}$ & $\Psi$ range $\left(^{\circ}\right)$ & $\begin{array}{c}\text { band area as a } \\
\text { proportion of } r\end{array}$ \\
\hline $0-0.2$ & 0.0 to 11.5 & 1.257 \\
\hline $0.2-0.4$ & 11.5 to23.6 & 1.257 \\
\hline $0.4-0.6$ & 23.6 to36.9 & 1.257 \\
\hline $0.6-0.8$ & 36.9 to 53.1 & 1.257 \\
\hline $0.8-1.0$ & 53.1 to 90.0 & 1.257 \\
\hline
\end{tabular}

Table 3. Band surface areas for equal height bins

Figure $11 \mathrm{a}$ and $\mathrm{b}$ show the orientation data plotted as frequency polygons for the data in equal increments of $\Psi$. The dashed line shows the isotropic case and a degree of scatter about the isotropic case can be seen in the results.

Figure $12 \mathrm{a}$ and $\mathrm{b}$ show the orientation data plotted as frequency polygons for the data in equal increments of $\sin \Psi$. This method of plotting is considered more comparable as each frequency total considers the same band surface area and hence is subject to similar uncertainty. On these plots the isotropic case would correspond to a horizontal line at $20 \%$ ( 5 equal height bins).

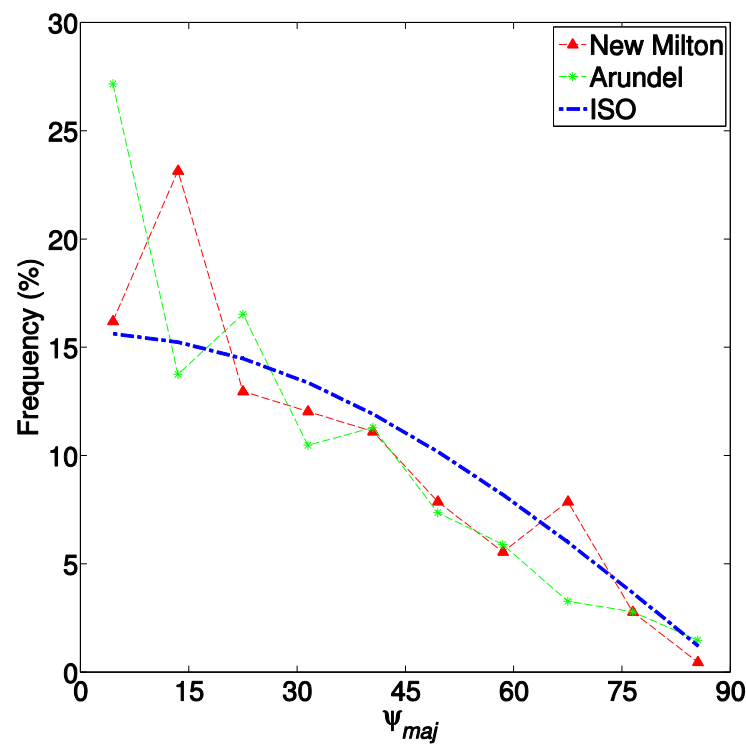

Figure 11: Equal angles scattered 

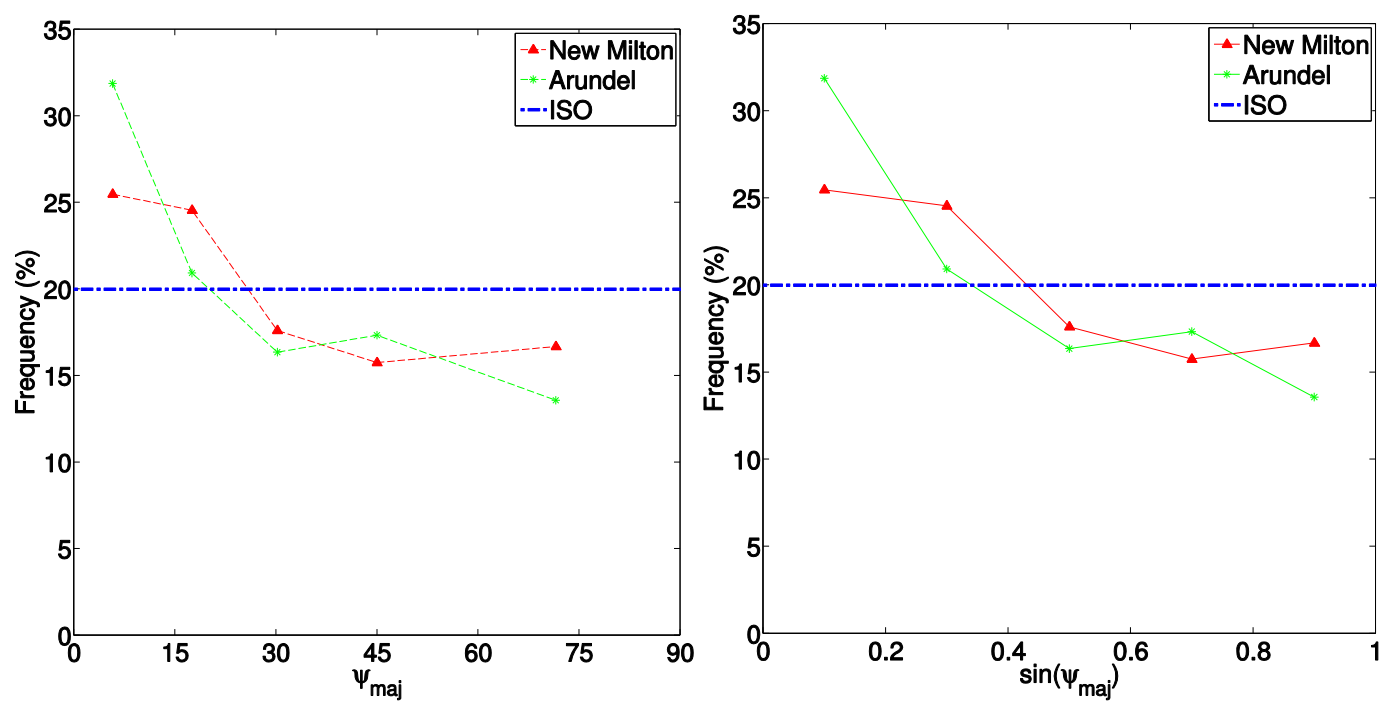

Figure 12: Equal areas (a) $\mathrm{x}$-axis by angle (b) $\mathrm{x}$ axis by sine $\Psi$

The orientation plots show that there is a higher proportion of particles oriented nearer to the horizontal than would be the case if the distribution were isotropic. This is perhaps as a result of trafficking although more work is needed to establish an orientation data curve for freshly placed ballast.

\section{Conclusions}

For the first time a method has been presented for obtaining samples of railway ballast with the in-situ fabric intact. The ability of powerful industrial CT scanners to scan through ballast/resin samples up to $300 \mathrm{~mm}$ in diameter has been demonstrated. Some illustrative results of the analysis of fabric using the CT scans have been presented, demonstrating the determination of coordination number and particle orientation distribution. Future work will focus on detailed comparative analyses of recovered samples to investigate quantitatively the development of fabric and its effect on the mechanical behaviour of ballast.

\section{Acknowledgements}

This research was supported by the Engineering and Physical Sciences Research Council (grants EP/F062591 and EP/H044949). The authors are grateful to: George Murrell, Robin Bates, Dave Meacham and Mark Scott of Balfour Beatty Rail for arranging access to track renewals, Mark Mavrogordato, Dmitry Grinev, Richard Boardman and Ian Sinclair of $\mu$-vis for arranging CT scans and their assistance in using software, and Phil Guinness of Robnor Resins for his help in identifying suitable resins.

\section{References}

[1] R. Brewer, "Fabric and mineral analysis of soils", New York: John Wiley and Sons Inc, 1964 
[2] M. Oda, "Initial fabrics and their relations to mechanical properties of granular material", Soils and Foundations, 12(1). 1972.

[3] J. B. Burland, "On the compressibility and shear strength of natural clays", Geotechnique, Volume 40, No. 3, pages 329 to 378. 1990.

[4] M. Oda, \& K. Iwashita, (editors). "Mechanics of granular materials: an introduction", Rotterdam, A.A. Balkema. 1999.

[5] A. O'Brien, E. A. Ellis, \& D. Russell, "Old railway embankment fill laboratory experiments, numerical modelling and field behaviour", In Proc: Advances in Geotechnical Engineering. The Skempton Conference, Volume 2, pp. 911-921, London: Thomas Telford. 2004.

[6] A. Cresswell, "Block sampling and test sample preparation of locked sands", Geotechnique, 51, No. 6, 567. 2001.

[7] B. A. Hofmann, D. C. Sego, \& P. K. Robertson,.."In Situ Ground Freezing to Obtain Undisturbed Samples of Loose Sand", Journal of Geotechnical and Geoenvironmental Engineering, ASCE, Vol. 126 No. 11, 979-989. 2000.

[8] Klassen, M., Clifton, A. \& Waters, J. "Track Evaluation and Ballast Performance Specifications", Transportation Research Record, 1131, Performance of Aggregates in Railroads and Other Track Performance Issues, 35-44. 1987.

[9] C. R. I. Clayton, A. V. D. Bica,. \& S. R. Moore, "Resin impregnation technique for the determination of the density variations in completed specimens of dry cohesionless soil", Geotechnique, Vol. 44, Issue 1, 165 to 173. 1994.

[10] C. Abbireddy, "Particle Form and its Impact on Packing and Shear Behaviour of Particulate Materials", Doctor of Philosophy, University of Southampton. 2008.

[11] M. E. Barton, "Cohesive sands. The natural transition from sands to sandstones", In: Proceedings of the conference on Geotechnical engineering of hard soils - soft rocks, Athens, Greece. A.A. Balkema, 367. 1994.

[12] A. Cresswell \& W. Powrie, "Triaxial tests on an unbonded locked sand", Geotechnique, 54, No. 2, 107. 2004.

[13] J. Desrues, R. Chambon, M. Mokni, \& F. Mazerolle, "Void ratio evolution inside shear bands in triaxial sand specimens studied by computed tomography", Geotechnique, Volume 46, 529 to 546. 1996.

[14] Robnor. Resins Online [Online]. Available: http://www.resins-online.com [Accessed May 2012].

[15] MUVIS. " $\mu$-VIS: Multidisciplinary, Multiscale, Microtomographic Volume Imaging”, [Online]. Available: http://www.southampton.ac.uk/muvis/ [Accessed 2012].

[16] G. V. R. Watson, \& W. Powrie \& A. P. Blades, "Particle-scale classification and identification of the structure of processed municipal solid waste by CT scanning", In: Hyodo, Murata \& Nakata (eds.) International Symposium on Geomechanics and Geotechnics of Particulate Media. Ube, Yamaguchi, Japan: Taylor \& Francis Group. 2006.

[17] P. J. Barrett, "The shape of rock particles, a critical review", Sedimentology, 27, 291-303. 1980. 
[18] L. A. Feldkamp, L. C. Davis,. \& J. W. Kress, "Practical cone-beam algorithm", Journal of the Optical Society of America A, Volume 1. 1984.

[19] Nikon. „XT Software Suite“ [Online]. Available: http://www.nikonmetrology.com/en_EU/Products/X-ray-and-CTInspection/Software/XT-Software-Suite [Accessed May 2012].

[20] VSG, "Avizo Fire Version 7: 3D Analysis Software for Material Science" [Online]. Available: http://www.vsg3d.com/avizo/fire [Accessed May 2012].

[21] Mathworks, "Matlab" [Online]. Available: http://www.mathworks.co.uk/products/matlab/ [Accessed May 2012].

[22] Fiji, "Trainable Segmentation Plugin Implementation", Available at: http://fiji.sc/Trainable_Segmentation_Plugin_Implementation [Accessed July, 2013].

[23] M. Hall, E. Frank, G. Holmes, B. Pfahringer, P. Reutemann \& I. H. Witten "The WEKA Data Mining Software: An Update", SIGKDD Explorations, 11(1). 2009.

[24] S. Beucher \& C. Lantejoul "Use of Watersheds in Contour Detection", Proc. Int'1. Workshop on Image Proc., CCETT, Rennes, France. 1979

[25] J. Russ, "The image processing handbook", 6th edition. CRC Press. 2011. 